\title{
Conforto termal como parâmetro de qualidade no trabalho em uma indústria de ração animal
}

A temperatura do ar e a umidade relativa do ar variam no decorrer do dia e do ano em ambientes produtivos, conforme os tipos e níveis de atividades executadas. Tais variações influenciam diretamente no conforto térmico dos trabalhadores, podendo afetar o desempenho e a produtividade. $O$ presente estudo teve por objetivo realizar a avaliação do conforto térmico dentro de uma fábrica de ração animal, considerando os parâmetros ergonômicos de satisfação térmica humana. Foi realizada uma análise do local e feita a coleta de dados de temperatura do ar e umidade relativa do ar durante as estações quente-seca e quente-úmida. Com isso, foi avaliado se havia conforto térmico usando o software de análises bioclimáticas Analysis Bio, sendo encontradas condições desconfortáveis em boa parte do tempo. Assim foram propostas algumas estratégias de melhoria das condições de conforto, utilizando medidas de ações corretivas e preventivas. Para o melhor cenário, foi proposto o uso de climatizadores e exaustores mecânicos, favorecendo a ventilação no local, em virtude do tipo de matéria-prima manufaturada.

Palavras-chave: Ergonomia; Conforto térmico; Estratégias bioclimáticas; Temperatura do ar

\section{Thermal comfort as a quality parameter at work in an animal feed industry}

\begin{abstract}
Air temperature and relative air humidity vary throughout the day and year in productive environments, depending on the types and levels of activities performed. Such variations directly influence the thermal comfort of workers, which can affect performance and productivity. The objective of the present study was to evaluate the thermal comfort within an animal feed factory, considering the ergonomic parameters of human thermal satisfaction. A site analysis was performed and data were collected on air temperature and relative humidity during hot-dry and hot-humid seasons. With this, it was evaluated if there was thermal comfort using the bioclimatic analysis software Analysis Bio, being found uncomfortable conditions in most of the time. Thus, some strategies to improve comfort conditions were proposed, using corrective and preventive actions. For the best scenario, it was proposed the use of air conditioners and mechanical exhausters, favoring the ventilation in the place, due to the type of manufactured raw material.
\end{abstract}

Keywords: Ergonomics; Thermal comfort; Bioclimatic strategies; Air temperature.

Topic: Construções e Arquitetura Sustentáveis

Reviewed anonymously in the process of blind peer.
Received: 02/10/2019

Approved: 26/11/2019
Mayara Júlia Silva do Nascimento

Universidade do Estado de Mato Grosso, Brasil

http://lattes.cnpq.br/7742058038437983

http://orcid.org/0000-0003-1763-8425

mayarajulia96@gmail.com

Jonathan Willian Zangeski Novais

Universidade de Cuiabá, Brasil

http://lattes.cnpq.br/5665663207008673

http://orcid.org/0000-0002-6598-3138

jonathan.novais@kroton.com.br

Thiago Fernandes (i)

Universidade Federal Rural da Amazônia, Brasil

http://lattes.cnpq.br/5470375744541646

http://orcid.org/0000-0001-7667-355X

thiago.ufra.pa@gmail.com
Referencing this:

NASCIMENTO, M. J. S.; NOVAIS, J. W. Z.; FERNANDES, T.. Conforto termal como parâmetro de qualidade no trabalho em uma indústria de ração animal. Revista Ibero Americana de Ciências Ambientais, v.10, n.6, p.154-162, 2019. DOI: http://doi.org/10.6008/CBPC2179$\underline{6858.2019 .006 .0014}$ 


\section{INTRODUÇÃO}

Segundo Frota et al. (2003), em regiões de clima quente e úmido as construções armazenam muito calor interno durante o dia, alcançando resfriamento somente a noite, quando a temperatura externa está mais agradável que o ambiente interno, de acordo com a inercia da construção. As variações de temperatura e umidade relativa do ar em locais de trabalho, estão diretamente ligadas com o conforto ambiental, que pode influir no conforto térmico do trabalhador e, consequentemente, ocasionar o stress térmico, aumento da tensão, afetando o desempenho dos trabalhadores, o que compromete sua produtividade física e mental (HOLMÉR, 2010).

No contexto industrial, o desconforto térmico é uma das principais causas de insatisfação nos locais de trabalho quando as pessoas estão expostas a ambientes térmicos quentes ou frios (MORGADO, 2015). Numa indústria cada vez mais qualitativa, quantitativa e, simultaneamente, competitiva, as tecnologias que concorrem para as diferentes funcionalidades se tornam de tal maneira especializadas que surgem 'gigantes' na produção de ração ou outras, não menos importantes, na área da ventilação e, nesta em particular, com um contributo, ainda que indireto, nas condições de conforto térmico, uma vez que é de extrema importância a manutenção de um ambiente que responda a condições de temperatura e umidade, previamente definidas, no fabrico da transformação de uma matéria-prima, neste caso, ração animal (MARTINS, 2011).

De acordo com Lamberts (2016), a performance humana, no exercício de atividades intelectuais, manuais e perceptivas, apresentam um melhor rendimento quando realizadas em ambientes confortáveis, que apresente boa climatização, iluminação e, principalmente, ventilação. Para Batiz et al. (2009) todos os seres humanos apresentam respostas comportamentais e fisiológicas às variações térmicas ambientais. A busca pelo bem-estar físico, fisiológico e psicológico humano vem de longa data, porém apenas nas últimas décadas têm se intensificado os estudos dos efeitos do conforto térmico sobre as pessoas em ambientes internos (LAMBERTS et al., 2003).

De tal maneira, problemas de exposição de colaboradores a temperaturas biologicamente desconfortáveis ao corpo humano, são comuns de serem encontrados, nesses locais de trabalho, necessitando de uma análise do conforto térmico no ambiente, de modo a averiguar as características do local e do trabalho exercido, definindo os princípios onde a intervenção ergonómica deve atuar. De acordo com a Associação Brasileira de Ergonomia (ABERGO, 2018), a aplicação da Ergonomia, no âmbito da atividade do trabalho, em abordagem interdisciplinar, é essencial para a produção de produtos mais competitivos e amigáveis e para a melhoria da produtividade organizacional.

Cartas bioclimáticas são um método interessante de verificar o conforto térmico de uma edificação. A primeira carta bioclimática surgiu na década de 1960, por meio dos estudos bioclimatológicos na arquitetura de Olgyay, definindo as condições de conforto térmico humano propondo um processo de construção dividido em clima, biologia, tecnologia e arquitetura, com estratégias de adaptação da edificação ao clima, a partir de dados climáticos externos (OLGYAY, 1963).

Anos mais tarde, na década de 1970, Givoni sob os estudos de Olgyay, concebeu uma Carta 
Bioclimática para Edifícios (Building Bioclimatic Chart - BBCC) que corrigia algumas limitações da carta idealizada por Olgyay, que tinha por pressuposto que as temperaturas do ar no exterior e no interior das edificações eram aproximadamente iguais. Givoni buscou relacionar o homem, o clima e a arquitetura, analisando as trocas de calor existente entre o homem e o meio, quanto à pressão atmosférica e os efeitos biofísicos dos fatores ambientais (GIVONI, 1976; LAMBERTS et al., 2014). Assim o objetivo deste trabalho foi realizar uma avaliação das condições termais do ambiente construído, e destes com os parâmetros ergonômicos previstos, propondo medidas corretivas as necessidades encontradas, buscando prover um ambiente termicamente confortável aos colaboradores.

\section{MATERIAIS E MÉTODOS}

\section{Local de estudo}

O estudo foi realizado em uma fábrica de ração, situada no município de Barra do Bugres/MT, estado de Mato Grosso. O clima local é considerado como Aw, conforme a classificação de Köeppen (ALVARES et al., 2013). É utilizado na fábrica o sistema pós-moagem, em que as matérias-primas utilizadas, neste caso, o milho, o farelo de soja e a torta de algodão, são processadas na mesma peneira. Na produção de ração farelada, utiliza-se basicamente o misturador helicoide - forma de hélice caracol, em que o misturador de ração está posicionado posterior ao moinho. No sistema de pós-moagem, é utilizada uma estrutura mais uniforme, pois, necessita de menos silos e um sistema de transporte considerado mais simples.

A fábrica de ração em estudo é considerada de médio porte, e conta com 15 funcionários, distribuídos em todo o sistema fabril, desde a produção, carregamento e estoque dos produtos acabados. $O$ carregamento dos sacos de $25 \mathrm{~kg}$ é realizado manualmente, utilizando uma esteira, com o posicionamento do veículo transportador estacionando sempre a direita, próximo a expedição. A expedição em sacas de $1000 \mathrm{~kg}$ é realizada utilizando uma máquina empilhadeira. A área de estoque situa-se atrás da indústria, em um barracão independente, e nesse estudo, não foi apresentado no layout. Os pontos marcados por " $X$ ", alinham os locais da realização das coletas, locais próximos onde os trabalhadores permanecem durante a produção da ração, conforme evidenciado na Figura 1.

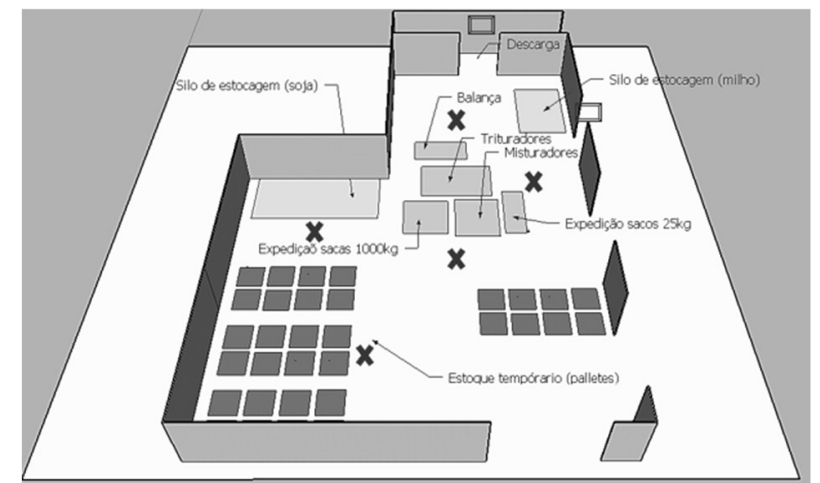

Figura 1: Layout da fábrica de ração. Os pontos em X foram os locais de coleta.

A estrutura conta com uma entrada frontal, três laterais e uma no fundo, que dá acesso à área de descarga da matéria prima. A entrada por onde os caminhões descarregam a matéria prima não possui 
portão, e nesta parede se localiza um dos exaustores, marcado por quadrados vermelhos, tal como acima da terceira entrada lateral.

\section{Coleta de dados}

Para mensuração das variáveis térmicas foi utilizado a Estação Meteorológica Kestrel 4500, fabricado pela empresa NK na região de Boothwyn localizada no estado da Pensilvânia, Condado de Delaware, U.S.A. Para quantificação desse estudo foram utilizados dados de umidade relativa do ar e as temperatura do ar de bulbo úmido e bulbo seco em ${ }^{\circ} \mathrm{C}$, com precisão de $\pm 1^{\circ} \mathrm{C}$.

Os dados foram coletados entre 08:00 e 16:30 horas, de acordo com o horário de funcionamento da indústria, sendo realizadas, as pausas para o almoço, entre 11:0 e 13:00 horas. Com os pontos fixos identificados, as medições foram realizadas num intervalo de 30 minutos, de modo, a respeitar o posicionamento de portas e janelas, e da produção da indústria, que permaneceu ativa durante todo período de coletas. Os dados foram anotados e posteriormente transferidos para planilhas eletrônicas. 0 estudo seguiu as mesmas abordagens metodológicas e sequencias operacionais de coleta de dados feitos por Silva et al. (2018), em que avaliaram o conforto térmico em habitações de interesse social, localizado no mesmo município. Foram feitas coletas em dois meses diferentes, de forma a seguir a sazonalidade do clima da região, sendo a primeira feita no mês de julho de 2018, período de seca, e a segunda em outubro de 2018, período de início das chuvas da região (ROCHA et al., 2018).

\section{Cartas bioclimáticas}

A carta bioclimática de Givoni (1992), relaciona a temperatura de bulbo seco com a umidade relativa do ar, e por meio dessa relação propõe-se uma zona de conforto e sugere medidas que buscam atingir conforto térmico quando o ponto de estudo está fora da área de conforto, quantificando a necessidade de estratégias passivas diante das condições climáticas oferecidas, ou ativas, quando necessárias para as condições internas da edificação (LAMBERTS et al., 2014).

As cartas foram geradas com o auxílio do software Analysis Bio, desenvolvido pela LABEEE Laboratório de Eficiência Energética em Edificações da Universidade Federal de Santa Catarina (UFSC). Esse software expõe o cenário de conforto térmico humano, com base em normais climatológicas ou dados climáticos horários existentes no formato TRY (Ano Climático de Referência, do inglês Test Reference Year) e, apresenta, as possíveis estratégias bioclimáticas para melhor adequação do ambiente, em formato de uma carta psicométrica.

A carta bioclimática agrupa os pontos em áreas de estratégias que podem ser utilizadas para melhorar o conforto térmico: A - Aquecimento artificial (calefação); B - Aquecimento solar da edificação/Aquecimento solar passivo; C - Massa térmica para aquecimento e aquecimento solar; D Conforto térmico; E - Umidificação; F - Desumidificação/Ventilação; G - Ventilação + Alta Inércia (massa térmica para resfriamento); H - Ventilação +Alta Inércia + Resfriamento Evaporativo; I - Alta inercia para resfriamento; J - Alta Inércia + Resfriamento evaporativo; K - Resfriamento evaporativo; L - Resfriamento 
artificial. A carta bioclimática de Givoni relaciona a temperatura de bulbo seco com a umidade relativa do ar, e por meio dessa conexão, propõe-se uma zona de conforto ideal para o exercício das funções de trabalho humano. Ainda, sugere medidas que buscam atingir conforto térmico, quando o lócus de estudo está fora da área de conforto, quantificando a necessidade de estratégias passivas diante das condições climáticas oferecidas, ou ativas, quando necessárias para as condições internas da edificação (LAMBERTS et al., 2014). Por fim, com a aplicação dos dados e seguindo os mesmos procedimentos feitos por Fernandes et al. (2019), foi possível elaborar as cartas bioclimáticas e discuti-las quanto a melhor estratégia de melhoria para o cenário.

\section{RESULTADOS E DISCUSSÃO}

Segue abaixo na figura 2 a caracterização microclimática da fábrica analisada.

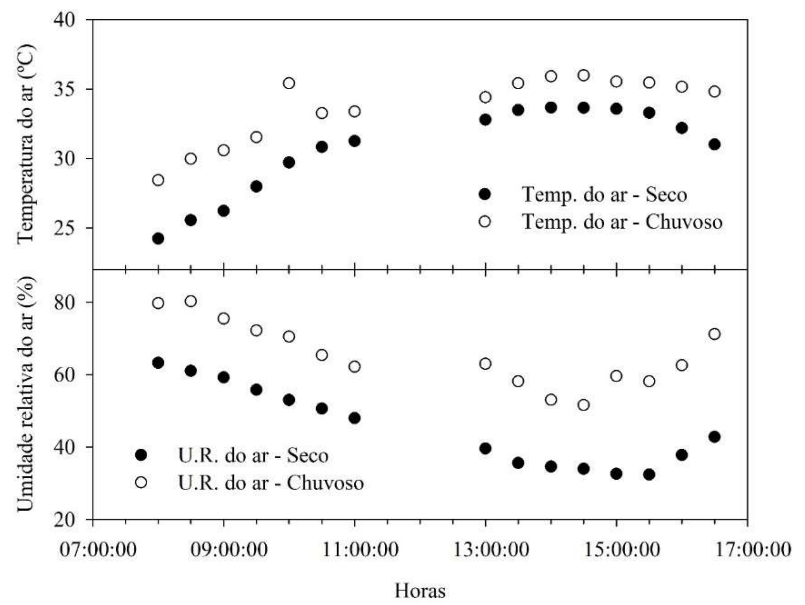

Figura 2: Temperatura do $\operatorname{ar}\left({ }^{\circ} \mathrm{C}\right)$ e umidade relativa do ar (\%) para o período seco e chuvoso.

Percebe-se pela figura 2 que as maiores temperaturas do ar e umidades relativas do ar ocorreram no período chuvoso, estando de acordo com o clima local. A maior temperatura observada ocorreu as 14:30 do período chuvoso, sendo aproximadamente 36 으.

A média de temperatura do ar do período seco foi 30,60 e 45,3 5 de umidade relativa do ar. Tanto as médias de temperatura do ar e umidade relativa do ar foram maiores no período chuvoso, sendo 33,7 ㅇ $\mathrm{e}$ $65,5 \%$ respectivamente, estando de acordo com outras pesquisas de conforto térmico realizadas no estado (NOVAIS et al., 2017; NOVAIS et al., 2018b). Segue abaixo na figura 3 a carta bioclimática do período seco, mês de julho, que corresponde ao inverno no hemisfério sul, caracterizada por temperaturas mais baixas no ano, baixo índice de precipitação pluviométrica e baixa umidade relativa do ar (ROCHA et al., 2018).

É possível observar que grande percentual dos dados climáticos estão fora dos limites da zona de conforto (em azul celeste), em que $25,3 \%$ dos dados estão na área de conforto, e os outros 74,4\% indicam desconforto térmico no ambiente, destacando-se $26,7 \%$ na área de Ventilação/Alta Inércia/ Resfriamento evaporativo e $42,7 \%$ na área de alta inércia/resfriamento evaporativo. A segunda carta bioclimática foi gerada para o período de início das chuvas da região, mês de outubro de 2019, conforme figura 4 abaixo. 


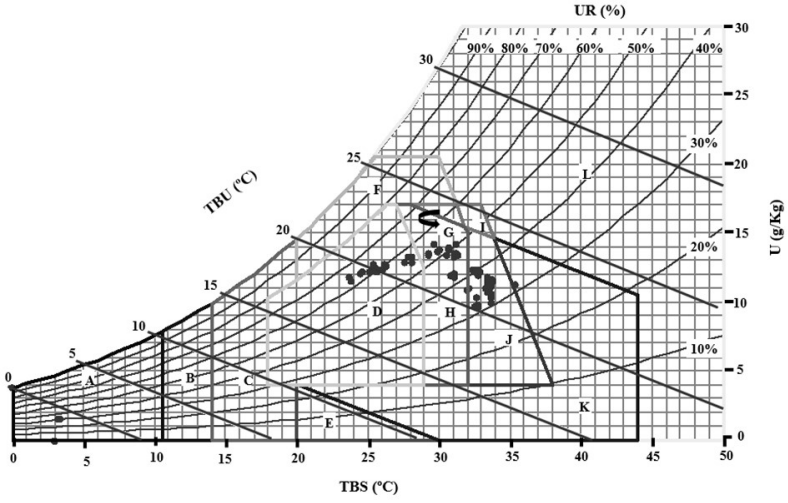

Figura 3: Carta bioclimática referente ao período seco de 2018.

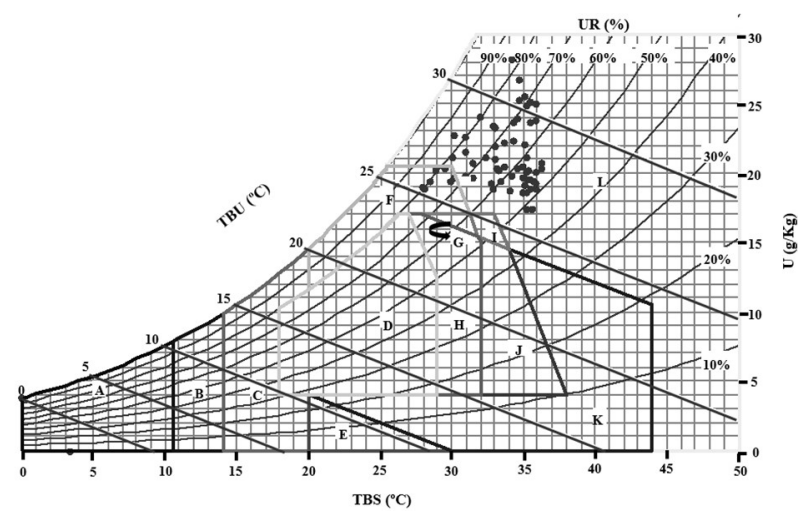

Figura 4: Carta bioclimática referente ao período chuvoso de 2018.

Para este período, $100 \%$ dos dados ficaram fora da zona de conforto térmico, em que a o uso de arcondicionado predomina na estratégia de melhorar o conforto térmico do local. Para este período a temperatura se torna elevada e a umidade relativa do ar aumenta, com a ocorrência de máximas superiores a 35ํ․ De acordo com as estratégias bioclimáticas apontadas pelos pontos plotados na carta, propôs-se medidas de ações corretivas que podem ser mais bem analisadas para o emprego em edificações em que ocorra desconforto similar.

A inércia térmica apontada nas estratégias está diretamente ligada as características dos componentes construtivos, tipo de piso, parede e cobertura, que atuam na capacidade de absorver, armazenar e dissipar calor. Tal estratégia deve ser melhor analisada em fase de projeto e construção, ou, caso de uma reforma completa da edificação. Em relação ao revestimento uma alternativa construtiva seria do Poliestireno Expandido (EPS), em que sua utilização já gerou a diminuição de até 7ํC em uma residência na cidade de Cuiabá (NOVAIS et al., 2014).

Dessa forma, buscou-se analisar medidas de controles que não necessitem atuar diretamente na estrutura do ambiente construído, mas que possa de igual forma agir sobre o desconforto térmico do ambiente. Assim como as estratégias bioclimáticas utilizadas no trabalho de Pacheco (2016), foram consideradas duas variações de ventilação do ambiente. A primeira, proporcionada por meio da ventilação natural, em que são controladas aberturas de portas e janelas, para renovação do ar, e a ventilação gerada. Porém, a estratégia, de ventilação natural, só deve ser empregada, quando a temperatura externa for superior a $20^{\circ} \mathrm{C}$, e a temperatura do ar externo for inferior a temperatura do ar interno (INMETRO, 2010).

Tal estratégia, indiretamente, já vem sendo empregada dentro da fábrica de ração, em que durante todo o processo produtivo as entradas e janelas do tipo basculante da edificação permanecem abertas. Contudo, com as altas temperaturas externas, somente esta ação não tem sido suficiente. Outra forma de promover a ventilação dentro do ambiente é por sistema de ventilação mecânica: exaustores e ventiladores. O local de estudo, conta com dois exaustores industriais na parede, sendo um na lateral direita a cima de umas das entradas e outro no fundo da edificação, e quatro ventiladores axiais em suporte, sendo dois próximos ao triturador, e dois próximos ao local de estocagem temporária, que ajudam na renovação do ar, e exaustão tanto do ar quente quanto das partículas volantes provenientes da produção da ração.

Segundo Lamberts et al. (2014), dentro de uma edificação o ar quente tende a se acumular nas partes 
mais elevadas do interior, a retirada deste ar quente pode criar um fluxo de ar ascendente gerado por aberturas em diferentes níveis. Um meio que pode ser adotado para criação deste efeito, é a adoção de exaustores eólicos, que dissipam o calor produzido pela energia radiante produzida pelo sol, elevado pelo aquecimento do telhado e o processo interno de geração de calor, que pode se estratificar conforme à altura do ambiente; eliminando assim a diferença entre as temperaturas do interior e exterior à edificação. Como o telhado do edifício é alto, os exaustores eólicos seriam uma boa opção para a retirada do ar quente, para uma maior abrangência de área ventilada. Contudo a alocação de mais exaustores de parede também pode ser alternativa válida, por possuir boa relação custo benefício.

A adoção de climatizador evaporativo seria uma estratégia para atuar na aclimatização do ar por resfriamento artificial combinada com o resfriamento evaporativo. Os climatizadores quando combinados com exaustores, podem gerar ótimos resultados refrigerativos, com eficiência energética, renovação rápida do volume de ar interno do ambiente e melhor qualidade do ar (LOTTI et al., 2006). Este sistema de resfriamento utiliza a transição da fase de água no estado líquido para o vapor de água (evaporação), para reduzir a temperatura do ar seco. Esse trabalho, utiliza menos energia do que a refrigeração dos condicionadores de ar convencionais, podendo alcançar uma economia de até $95 \%$. Além disso, não é necessário realizar o fechamento de entradas e saídas, assim como de janelas, o que ajudará na circulação do ar interno e no processo de desumidificação do ar, que pode ser controlado adicionando ou retirando vapor do ambiente (DUL et al., 2012).

Outra aplicação similar foi feita por Fernandes et al. (2019), em que aplicou também a Carta Bioclimática de Givoni (1992), na avaliação do conforto térmico de um centro de assistência social, também em Barra do Bugres/MT, mostrando que no período matutino, prevaleceu a sensação de estresse e desconforto térmico em toda percentagem de horas analisada, mostrando a real necessidade de circulação do ar dentro do ambiente. Observou-se também a necessidade de melhoramento em quase $100 \%$ das horas com sombreamento adequado, ventilação natural e ar condicionado para equilibro da temperatura e umidade do ar interna, com o intuito de contribuir com a saúde ocupacional, gerando um conforto adequado aos indivíduos que precisam desses serviços.

Uma alternativa sustentável seria a utilização de uma maior quantidade de arborização no entorno da fábrica (ANDRADE et al., 2016; NOVAIS et al.; 2017). A arborização interage com a radiação solar, interceptando, refletindo e absorvendo (NOVAIS et al., 2018a) sendo uma boa estratégia para garantir conforto térmico em climas tropicais úmidos (NOVAIS et al., 2015).

Atualmente existem diretrizes legais no âmbito nacional e internacional, que regulamentam os limites de tolerância a exposição ao calor, e as medidas a serem tomadas pelo empregador, que vai desde adaptação do local de trabalho ao colaborador, como prevê as bases ergonômicas, desde ao adicional de insalubridade.

De acordo com a NR 15 (BRASIL, 1978), quando as temperaturas previstas em seus níveis de ação forem excedidas, o empregador deve promover a aclimatação dos trabalhadores expostos ao calor, entendendo-se por aclimatação: 'a adaptação fisiológica gradual do indivíduo, cuja resposta é a melhora da 
capacidade para suportar a sobrecarga térmica'.

Como medidas preventivas de modo a evitar a sobrecarga térmica, o anexo 3 prevê: a disponibilização de bebidas frescas, de modo suficiente a repor a água do organismo; fornecimento de vestimentas de trabalho adaptadas quanto a natureza da atividade exercida; programação dos trabalhos em períodos e condições térmicas mais amenas, especialmente os mais pesados, que devem ser mais lentamente, ou intercaladas com pausas, para permitir que o corpo elimine calor adicional gerado pelo metabolismo (DUL et al., 2012), com permissão para autolimitação da exposição; conceder informação e capacitação aos trabalhadores; além do acompanhamento médico.

\section{CONCLUSÕES}

Com o estudo foi constatado o desconforto térmico dentro da indústria de ração, com um percentual considerável de horas do dia com sensação de desconforto térmico, conforme as simulações realizadas. Os resultados obtidos mostram que um sistema de aclimatização eficiente se faz necessário dentro do local, haja visto que os sistemas de ventilação atuais não têm sido suficientes. Por conseguinte, a sustentabilidade ambiental bem como a qualidade da saúde do indivíduo serão fatores a ter em consideração, daí a ventilação natural deter um ponto fulcral para o desenvolvimento de projetos que apostem nessas áreas aliando com o conforto térmico do indivíduo.

\section{REFERÊNCIAS}

ABERGO. Associação Brasileira de Ergonomia. O que é ergonomia?. Rio de Jeneiro: ABERGO, 2018.

ALVARES, C. A.; STAPE, J. L.; SENTELHAS, P. C.; GONÇALVES, J. L. M.; SPAROVEK, G.. Koppen's climate classification map for Brazil. Meteorologische Zeitschrift, v.22, n.6, p.711-728, 2013. DOI: http://doi.org.10.1127/0941-2948/2013/0507

ANALYSIS BIO. Programa Analysis Bio: modulo bioclimatologia. Versão 2.1.5. Florianópolis: Universidade Federal de Santa Catarina, 2009.

ANDRADE, L. P.; NOVAIS, J. W. Z.; DE MUSIS, C. R.; SANCHES, L.; PEREIRA, S. P.. Efeitos de borda sobre o microclima de um parque ecológico urbano em Cuiabá/MT. Revista Estudo Debate, Lajeado, v.23, n.2, p.180-194, 2016. DOI: http://dx.doi.org/10.22410/issn.1983036X.v23i2a2016.1078

BATIZ, E. C.; GOEDERT, J.; MORSCH, J. J.; KASMIRSKI JUNIOR, P.; VENSKE, R.. Avaliação do conforto térmico no aprendizado: estudo de caso sobre influência na atenção e memória. Production Journal, v.19, n.3, p.477-488, 2009. DOI: http://dx.doi.org/10.1590/\$0103-65132009000300006

DUL, J.; WEERDMEESTER, B.. Ergonomia prática. 3 ed. São Paulo: Blucher, 2012.

FERNANDES, T.; BORGES, R. T.; NOVAIS, J. W. Z.; CURVO, A. D.; NASCIMENTO, V. L.; SILA JUNIOR, M. A.; FERNANDES, T.. Evaluation of thermal comfort environment in a unit of the Reference Center of Social Assistance (CRAS). Research, Society and Development, v.8, n.4, p.484957, 2019. DOI: http://dx.doi.org/10.33448/rsd-v8i4.957

FROTA, A. B.; SCHIFFER, S. R.. Manual do conforto térmico: arquitetura, urbanismo. 6 ed. São Paulo: Studio Nobel, 2003.

GIVONI, B.. Man, climate and architecture. Londres: Applied Science Publishers, 1976.

GIVONI, B.. Comfort, climate analysis and building design guidelines. Energy in Buildings, v.18, p.11-23, 1992.

HOLMÉR, I.. Climate change and occupational heat stress: methods for assessment. In: GLOB HEALTH ACTION, 3. Anais. 2010 .

INMETRO. Instituto Nacional de Metrologia, Qualidade e Tecnologia. Regulamento Técnico da Qualidade para o nível de Eficiência Energética Edificações Residenciais. Anexo da portaria INMETRO n.449/2010. Rio de Janeiro: INMETRO, 2010.

LAMBERTS, R.; XAVIER, A. A. P.. Conforto térmico em ambientes internos. Florianópolis: Laboratório de Eficiência Energética em Edificações, 2003.

LAMBERTS, R.; DUTRA, L.; PEREIRA, F.. Eficiência Energética na Arquitetura. 3 ed. Rio de Janeiro: Eletrobras Procel, 2014.

LAMBERTS, R.. Desempenho térmico de edificações. ECV 5161. Florianópolis: Universidade Federal de Santa Catarina, 2016.

LOTTI, L. B.; RUSSO, M. I. A. F.; BACCI, M. D. N.; PRADO, N. F. 
F.. Substituição dos aparelhos de ar-condicionado por resfriadores evaporativos na Faculdade de Engenharia Mecânica da UNICAMP. Revista Ciências do Ambiente OnLine, Campinas, v.2, n.2, 2006.

MARTINS, A. M Q.. Conforto térmico na indústria do papel. Dissertação (Mestrado em Engenharia de Segurança e Higiene Ocupacionais) - Faculdade de Engenharia da Universidade do Porto, Lisboa, 2011.

BRASIL. Ministério do Trabalho e Emprego. Portaria n.3.214 de jul. 1978. Normas regulamentadoras de segurança e saúde no trabalho (NR-15): atividades e operações insalubres. Brasília, 1978.

MORGADO, M.; TALAIA, M.; TEIXEIRA, L.. A new simplified model for evaluating thermal environment and thermal sensation: An approach to avoid occupational disorders. International Journal of Industrial Ergonomics, v.60, p.3-13, 2015. DOI: http://doi.org/10.1016/j.ergon.2015.11.001

NOVAIS, J. W. Z.; OLIVEIRA, E. V.; JOAQUIM, T. D.; LEAL, L. A.; NOGUEIRA, M. C. J. A.; SANCHES, L.. Comparação do Desempenho Térmico de Painéis em EPS como Alternativa aos Tijolos Cerâmicos no Conforto Térmico de Residências em Cuiabá/MT. Unopar Científica e Tecnológica, v.13, n.1, p.39-43, 2014.

NOVAIS, J. W. Z.; JOAQUIM, T. D. O.; ALMEIDA, F. M.; ZUFFO, M.; NOGUEIRA, M. C. D. J. A.; LEAL, L. A.; RODRIGUES, A. B. C.; KUNZ, F. O.. Conforto térmico de um laboratório da Universidade de Cuiabá-UNIC. Revista Eletrônica em Gestão, Educação e Tecnologia Ambiental (REGET), Santa Maria, v.19, n.3, p.504-812. 2015. DoI: http://dx.doi.org/10.5902/2236117018425

NOVAIS, J. W. Z.; FARIAS, F. M.; SILVA REIS, N. M.;
MARQUES, A. C. A.; SIQUEIRA, A. Y.; JOAQUIM, T. D. O.; RIBEIRO, B. V.. A melhoria climática e conforto térmico proporcionado pela arborização em uma escola estadual em Várzea Grande/MT. Revista da Sociedade Brasileira de Arborização Urbana, v.12, n.3, p.1-14, 2017. DOI: http://dx.doi.org/10.5380/revsbau.v12i3.63546

NOVAIS, J. W. Z.; SANCHES, L.; DIAS, V. R. M.; MACHADO, N G.; SILVA, L. B.; AQUINO, A. M.. Variação espaço-temporal da PAR refletida pelo solo e transmitida pelo dossel em floresta inundável no Pantanal mato-grossense. Ciência Florestal, Santa Maria, v.28, n.4, p.1502-1513, 2018a. DOI: http://dx.doi.org/10.5902/1980509835097

NOVAIS, J. W. Z.; MARQUES, A. C. A.; SIQUEIRA, A. Y.; REIS, N. M. S.; PEREIRA, S. P.; JOAQUIM, T. D.; ZANGESKI, D. S. O.. Índice de Temperatura e Umidade (ITU) Visando o Conforto Térmico para o Parque Mãe Bonifácia, Cuiabá/MT. Ensaios e Ciência: C. Biológicas, Agrárias e da Saúde, v.22, n.2, p.6975, 2018b. DOI: http://dx.doi.org/10.17921/14156938.2018v22n2p69-75

OLGYAY, V.. Design with climate. Princeton: University of Princeton, 1963.

SILVA, N. K. F.; FERNANDES, T.; NOVAIS, J. W. Z.; FERNANDES, T.; CURVO, A. D.. Conforto Térmico em Habitações de Interesse Social: um Estudo Aplicado a uma Unidade de Saúde da Família. Uniciências, v.22, n.1, p.2-7, 2018. DOI: http://dx.doi.org/10.17921/14155141.2018v22n1p2-7

ROCHA, A. A.; NOVAIS, J. W. Z.; SOUZA, R. D.; SANTOS, A. R. C.; ALEIXES, V. F.. Caracterização da variabilidade climática em Diamantino/MT - Brasil no período de 1987 a 2017. Enciclopédia Biosfera, v.15, n.27, 2018. DOI: http://doi.org.10.18677/EnciBio 2018A7

A CBPC - Companhia Brasileira de Produção Científica (CNPJ: 11.221.422/0001-03) detém os direitos materiais desta publicação. Os direitos referem-se à publicação do trabalho em qualquer parte do mundo, incluindo os direitos às renovaç̃̃es, expansões e disseminações da contribuiç̃o, bem como outros direitos subsidiários. Todos os trabalhos publicados eletronicamente poderão posteriormente ser publicados em coletâneas impressas sob coordenação da Sustenere Publishing, da Companhia Brasileira de Produção Científica e seus parceiros autorizados. Os (as) autores (as) preservam os direitos autorais, mas não têm permissão para a publicação da contribuição em outro meio, impresso ou digital, em português ou em tradução. 